\title{
Intergenerational wealth inequality and transfer in shared socioeconomic pathways A case study of South Africa
}

Soheil Shayegh ( $\square$ soheil.shayegh@eiee.org )

Centro Euro-Mediterraneo sui Cambiamenti Climatici https://orcid.org/0000-0002-8960-8244

\section{Yu Zheng}

CEPII: Centre d'Etudes Prospectives et d'Informations Internationales

\section{Research Article}

Keywords:

Posted Date: February 4th, 2022

DOI: https://doi.org/10.21203/rs.3.rs-1299984/v1

License: (c) (1) This work is licensed under a Creative Commons Attribution 4.0 International License.

Read Full License 


\title{
Intergenerational wealth inequality and
}

\section{transfer in shared socioeconomic pathways:}

\section{A case study of South Africa}

\author{
Soheil Shayegh ${ }^{1^{*}}$ and Yu Zheng ${ }^{2 \dagger}$ \\ $1^{*}$ RFF-CMCC European Institute on Economics and the \\ Environment (EIEE), Centro Euro-Mediterraneo sui \\ Cambiamenti Climatici, Milano, Italy. \\ ${ }^{2}$ CEPII-CIREM, Centre d'Études Prospectives et d'Informations \\ Internationales, France.
}

*Corresponding author(s). E-mail(s): soheil.shayegh@eiee.org; Contributing authors: alpsrain@gmail.com; †These authors contributed equally to this work.

\begin{abstract}
We develop a novel structural economic model of overlapping generations to study wealth accumulation and distribution under the shared socioeconomic pathways (SSPs). We consider skill-specific wages and intergenerational wealth transfers as determinants wealth. The model is calibrated to match the projections of human capital accumulation and economic growth of South Africa in the $21^{\text {st }}$ century. We find that the wealth gap between the rich and the poor increases under the SSP3 and SSP4 scenarios which have lower human capital growth rates. Furthermore, rich households accumulate more wealth at a faster rate than poor households. In other scenarios, the median households with mixed skill background are those leading the wealth accumulation compared to rich households. As a result, the wealth gap grows slower and the wealth inequality measured by the Gini index decreases in SSP1, SSP2, and SSP5. Overall, our results highlight the important role of capital inheritance in the income distribution dynamics.
\end{abstract}




\section{Introduction}

Wealth distribution, inequality and their relationship with economic development have been the subject of a dynamic and ever-changing research in the past few decades (Ahluwalia et al, 1976; Anand and Kanbur, 1993; Stewart, 2016). Adding to this debate is the emergence of "sustainable development" narrative (Hopwood et al, 2005), the recent concerns over environmental issues such as climate change, and their broader impacts on economic growth and socioeconomic inequalities (Doyle and Stiglitz, 2014). Therefore, the relationship between inequality and development is a multifaceted problem which can be analyzed from the perspective of labor, including skill-biased technological change (Acemoglu, 2002) and education (Aghion, 2002), or by considering macroeconomic factors such as trade between developing and developed countries (Acemoglu, 2003; Grossman and Helpman, 2018) and climate-induced migration (Shayegh, 2017).

Furthermore, analysing the prospect of inequality in a broader context of future socioeconomic development adds yet another layer of complexity to this evolving concept (Hillebrand, 2008; Rougoor and Van Marrewijk, 2015). One way to address this problem is through developing scenarios that are capable of capturing the essential characteristics of future economic growth, human development, and environmental change in a consistent way (Kok et al, 2015). Shared Socioeconomic Pathways (SSPs) are a set of five distinct scenarios developed to describe future social economic scenarios with different challenges for climate change adaptation and mitigation (O'Neill et al, 2014). Across the SSPs, inequality is one of the key themes in defining the underlying narratives. The main drivers of inequality within different SSPs can be identified as technological growth, economic development (e.g., global and regional GDP), and demographics factors (e.g., population and education attainment, Samir and 
Lutz, 2017). Although these factors are explicitly quantified within each SSP and for each single country, income inequality has only been qualified in these SSPs as part of their narratives, and has not been quantified explicitly in the form of Gini index or other inequality measures. Recent attempts to quantify inequality within the SSP framework rely on econometric estimation of country-specific Gini index based on other socioeconomic factors and project it to the future (Rao et al, 2019). However, this and other similar studies are mainly focused on income inequality and ignore the broader question of wealth inequality and the role of capital accumulation and intergenerational transfers (Wolff, 2002). Other studies have taken yet a different approach by investigating inequality between the regions (Denniga et al, 2015) and under different climate change future impacts (King and Harrington, 2018).

Overall and despite a growing interest in this topic, attempts to model wealth distribution and inequality dynamics have been limited in scope, mainly because wealth distribution is more complicated to model as wealth is an accumulation process which is very domain specific (Nolan et al, 2021). Wealth can be transferred horizontally across one generation and among different subpopulations (Benhabib et al, 2017; Berman et al, 2016) or vertically within one sub-population from one generation to future generations (Elinder et al, 2018). Some studies use the Pareto distribution theory to capture the inequality dynamics at the individual level within a generation (Gabaix et al, 2016; Jones and Kim, 2018). Other studies have used overlapping generation (OLG) modeling to highlight the importance of considering the joint distribution of retirement wealth and life earnings in wealth inequality calculations (Hendricks, 2007). There are also studies using a general equilibrium OLG model to describe the intergenerational links through bequest motives and earning ability that can explain the wealth accumulation across generations (De Nardi, 
2004) and the wealth dispersion at the retirement age of one generation (De Nardi and Yang, 2014). Finally, by including labor income and capital income risk in an OLG framework, Benhabib et al (2011) have modeled the inter-generational transmission of wealth and show that capital income risk has a fundamental role in affecting wealth distribution.

Our paper contributes to the literature by providing a fresh perspective on the interplay between income and capital under different socioeconomic conditions laid out by the SSP scenario framework. In particular, we study the dynamics of wealth inequality and distribution in South Africa in the $21^{\text {st }}$ century under five SSPs. We develop an OLG model which follows human capital accumulation and economic growth trajectories of each SSP, through allocating skill-specific labor to different sectors and allowing for skill-differentiated capital inheritance from one generation to next. The contribution of our paper to the field of sustainable development and inequality is three fold. First, to the best of our knowledge, we are the first to utilize a structural model (i.e., the OLG model) in the SSP framework to analyze the wealth creation and transfer dynamics. Second, we quantify the heterogeneity in wealth dynamics among different sub-populations including the richest, the poorest, the average, and the median households under different SSP scenarios. Third and most importantly, our model demonstrates the important role of wealth inheritance in the income distribution dynamics. Indeed, to echo with Piketty and Zucman (2015), we show that in the scenarios where there are slower economic growth and lower human capital outlook, inequality rises sharply due to much higher wealth concentration and capital inheritance within the wealthiest subpopulations. Historical data from the U.S. and Europe also show that the rising top income share in the U.S. and Europe has mostly been driven by capital income (Nolan et al, 2021; Piketty et al, 2018; Saez and Zucman, 2016). 
The remaining of the paper is organized as follows. Section 2 provides a background for wealth inequality in South Africa. Section 3 briefly describes a sketch of the model (see the Appendix for details). Section 3 describes the inputs to the model from the SSP scenarios and the results in terms of wealth distribution and wealth dynamics. Section 4 provides the conclusion with broader implications of the findings.

\section{Wealth Inequality in South Africa}

South Africa has suffered centuries of unequal distribution of land, water, minerals, investment capital, and human capital along racial and ethnic lines (Wilson, 2011). As a result and despite having a progressive constitution and a democratic system, it is still suffering from one of the largest inequality gaps in income distribution in the world (Francis and Webster, 2019). According to latest available data from the World Bank, the Gini index in South Africa was at 63 in 2014, the largest among 83 countries with an estimated Gini index 1. While historically, most studies have focused on describing and analysing income inequality (Leibbrandt et al, 2012), wealth inequality and its pervasiveness in the South African society has come under scrutiny only very recently and as part of a broader debate over government fiscal policies in response to historic inequalities and recent COVID-19 related economic hardship (Arendse and Stack, 2018; Chatterjee et al, 2021). Using historical records of tax micro data, household surveys, and macroeconomic balance sheet statistics, it has been shown that the top 10 per cent own 86 per cent of aggregate wealth in South Africa and such high levels of inequality in wealth distribution has stayed unchanged since the transition from apartheid to democracy (Chatterjee et al, 2020). Some studies have suggested that imposing a wealth tax could address

\footnotetext{
${ }^{1}$ see "World Development Indicators" at https://datacatalog.worldbank.org/dataset/worlddevelopment-indicators
} 
underlying economic inequality and tax deficits to some degree (Arendse and Stack, 2018). However, the feasibility and effectiveness of such policy proposals highly depend on the future socioeconomic and political development in South Africa which will directly impact the wealth creation, accumulation and distribution among different sub-populations. This calls for the development a modeling framework capable of comparing wealth inequality under different socioeconomic scenarios.

Inheritance tax on the other hand has been regulated in South Africa through a series of laws including the Administration of Estates Act (Act 66 of 1965), the Wills Act (Act 7 of 1953), the Intestate Succession Act (Act 81 of 1987), and the Estate Duty Act 45 of 1955. According to the Estate Duty Act, the inheritance applies to the estates whose value exceeds R3.5 million (about 225,000 USD). The tax rate is $20 \%$ for estates up to R30 million (about 2 million USD) and 25\% for everything beyond (EXPATICA, 2021). Therefore, any comprehensive analysis of wealth transfer and inequality in South Africa should consider not only the inheritance dynamics but the implications of Estate Duty laws. In this paper, we take a first step in this direction by introducing a simple model of intergenerational wealth transfer for South Africa.

\section{Modeling Inequality in the SSP framework}

We model the directed technical change with labor reallocation in an overlapping generations model (OLG) (Diamond, 1965; Galor, 2011; Casey et al, 2019). We use the population, education, and economic output projections under five SSP scenarios to calibrate our model. Each SSP scenario is developed around a very distinct narrative about the future technological and socioeconomic growth and their interaction with the environment. SSP2 represents the 
middle-of-the-road scenario with medium population development and economic growth. SSP1 is the sustainability pathway where inequality is lessened, and technological change is directed to the environmental aspect. SSP5 is a scenario with high human capital and technological growth based on fossil-fuel development. SSP3 and SSP4 are the two rocky pathways to sustainability where in SSP3, there is a rapid growth in population but lower investment in human capital, and a slower economic growth. SSP4 narrates an unequal regional economic/technological development.

Our model assumes two economic sectors: agriculture and non-agriculture. Each sector uses a specific type of labor (i.e., low-skilled labor in agriculture and high-skilled labor in non-agriculture). Individuals in this model live through two periods of 20-year length. They are children in the first period requiring parental resources for their education, and in the second period they are adults working and earning income and capital inheritance spending them on their consumption and raising children. The model is solved by maximizing parents' utility coming from their own consumption, capital they pass to their children, and their children's future wages. In the production side, labor and aggregated capital are the main inputs to the production in each sector while technological progress grows exogenously in each sector according to their calibrated growth rate under different SSP scenarios. Depending on their skill level, individuals inherit both productive and non-productive capitals from their parents. Their wealth therefore, comprises these inherited capitals from their parents and their own skill-specific wages. This model is able to capture the creation of wealth and its transfer from one generation to another. The detailed model is presented in the Appendix. 


\section{Results}

In this section, we present the results of the simulation of wealth dynamics in a stylized case of a developing country (South Africa) under 5 SSPs. We calibrate our economic model to replicate the economic output and human capital accumulation projections under these five scenarios in South Africa (Lutz et al, 2014). Figure 1 demonstrates the key inputs into the model: GDP under five SSP scenarios which provides the growth rate of technological change in equation 16 in the Appendix, and the high-skilled to low-skilled labor ratio under the SSP scenarios which helps us solve the parents' utility optimization equation at each period. Since each SSP scenario represents a distinct economic and human capital growth path, we expect the outcome of our OLG model indicate significant variations in wealth distribution and inequality across the SSP scenarios. For example, SSP1 represents the a sustainable pathway. As shown in panel (a) in figure 1, GDP grows substantially in this scenario while as shown in panel (b) the ratio of high-skilled to low-skilled labor reaches around 10. In contrast, more unequal SSPs such as SSP3 and SSP4 are associated with regional conflicts and disparities in economic opportunities which result in lower economic growth rates and stagnating human capital accumulation. 

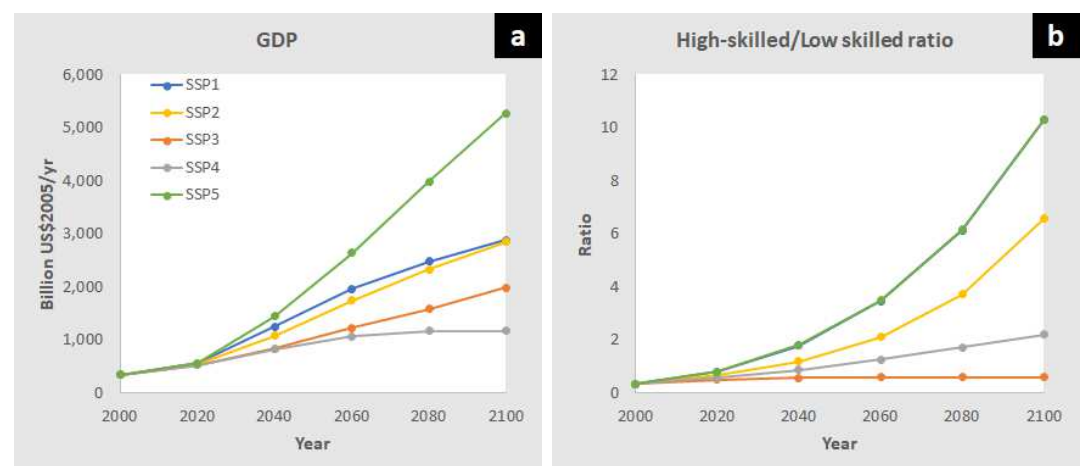

Fig. 1: The socioeconomic projections under the SSP scenarios in South Africa from 2000 to 2100. (a) GDP, and (b) high-skilled to low-skilled labor ratio from the Wittgenstein Centre projections (Lutz et al, 2014).

\subsection{Wealth distribution}

The model starts in year 2000 with two sub-populations of low-skilled and highskilled adults. Each adult then can have two types of children which generates 4 different types of adults in year 2020. Continuing this trend to 2100, there will be 64 sub-populations by the end of the century with mixed skill background. Within each generation we identify 4 sub-populations to showcase the results of our analysis: the richest group with purely high-skilled lineage, the poorest with purely low-skilled lineage, the average and the median sub-populations. The set of the results in figure 2 demonstrates the wealth dynamics over 5 generations in South Africa for each SSP scenario. Panel (a) in figure 2 shows the evolution of wealth among the wealthiest people under each SSP scenario. These results indicate that the accumulated wealth of the rich is about 130 times their initial wealth by the end of the century under SSP5. Interestingly, the rich will increase their wealth by a factor of 100 under SSP3 which is higher than the 80, 70, and 40 fold increases resulted in SSP2, SSP1, and SSP4 respectively. If we compare this pattern with the wealth growth among the poorest group in panel (b), we can make two observations: 
- The wealth grows much slower among the poor compared to the rich over generations and under all SSP scenarios. For example, in SSP5 the wealth only grows by a factor of 45 among the poor compared to 130 among the rich.

- While both the rich and the poor enjoy a fast growth of wealth under SSP5, the second fastest growth in wealth for the rich happens under SSP3 while for the poor it happens under SSP1 and SSP2.

As a result, we expect to see the wealth gap between the rich and the poor grows faster under SSP3 compared to other scenarios (see panel (a) in figure $4)$.

While focusing on the richest and the poorest sub-populations can provide some useful insights into the growing inequality between theses groups, it does not show how the wealth is distributed among other sub-populations. In panels (c) and (d) we provide wealth dynamics among the median and the average sub-populations. We observe that while both groups follow similar ranking of SSP scenarios in terms of wealth growth (i.e., SSP5 with the highest followed by SSP1 and SSP2 in the middle and SSP3 and SSP4 with the lowest growth rates), the wealth grows by about 4 to 5 times faster among the median populations than the average group. 

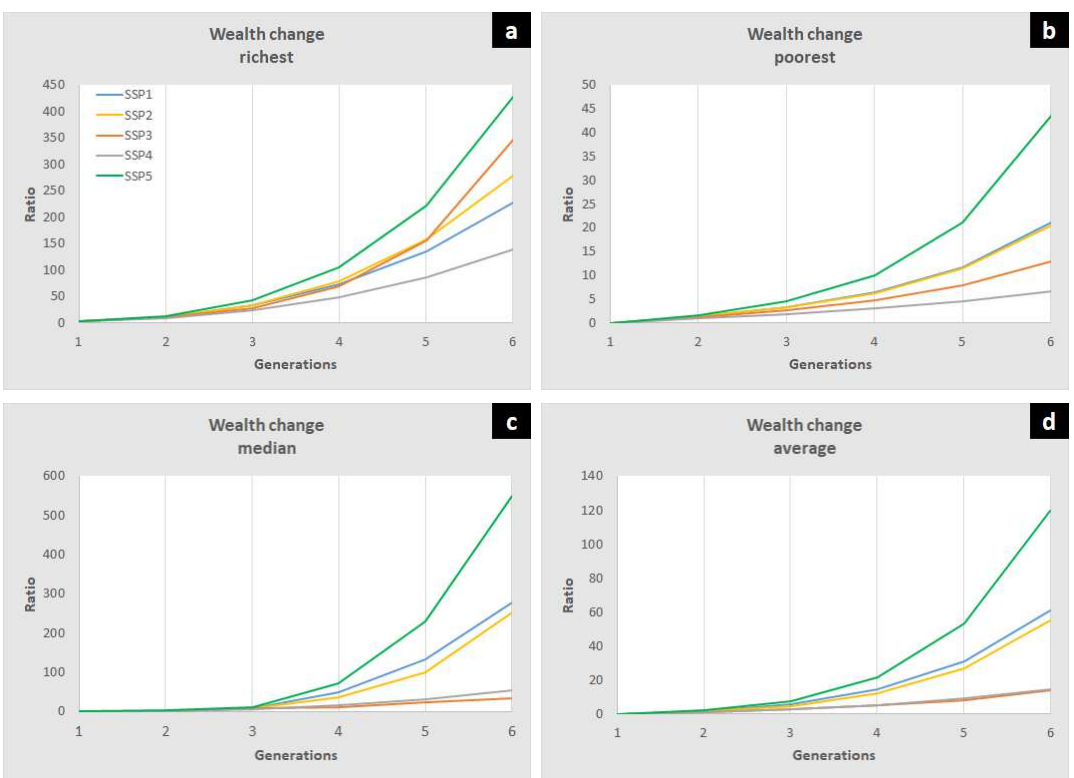

Fig. 2: Intergenerational wealth growth among different sub-populations under different SSPs: (a) richest, (b) poorest, (c) average, and (d)median. The results are reported as ratio of each sub-population's wealth in each generation to their initial wealth in year 2000 .

Another way of looking at these findings is by comparing the wealth growth among different sub-populations under each SSP scenario. Figure 3 compares the intergenerational wealth dynamic of the rich, the poor, the median, and the average groups under different SSP scenarios. While the rich's wealth accumulation is dominant under SSP3 and SSP4, the median group dominates wealth accumulation trends under SSP1, SSP2, and SSP5. This heterogeneity in wealth accumulation patterns has a broader impact on wealth distribution and inequality. As the rich group accumulates more wealth under SSP3 and SSP4 compared to other sub-populations, the wealth gap grows wider in these scenarios. On the other hand, the fast growth of wealth among the median group under SSP1, SSP2, and SSP5 helps close the wealth gap and improve inequality in wealth distribution under these scenarios. 

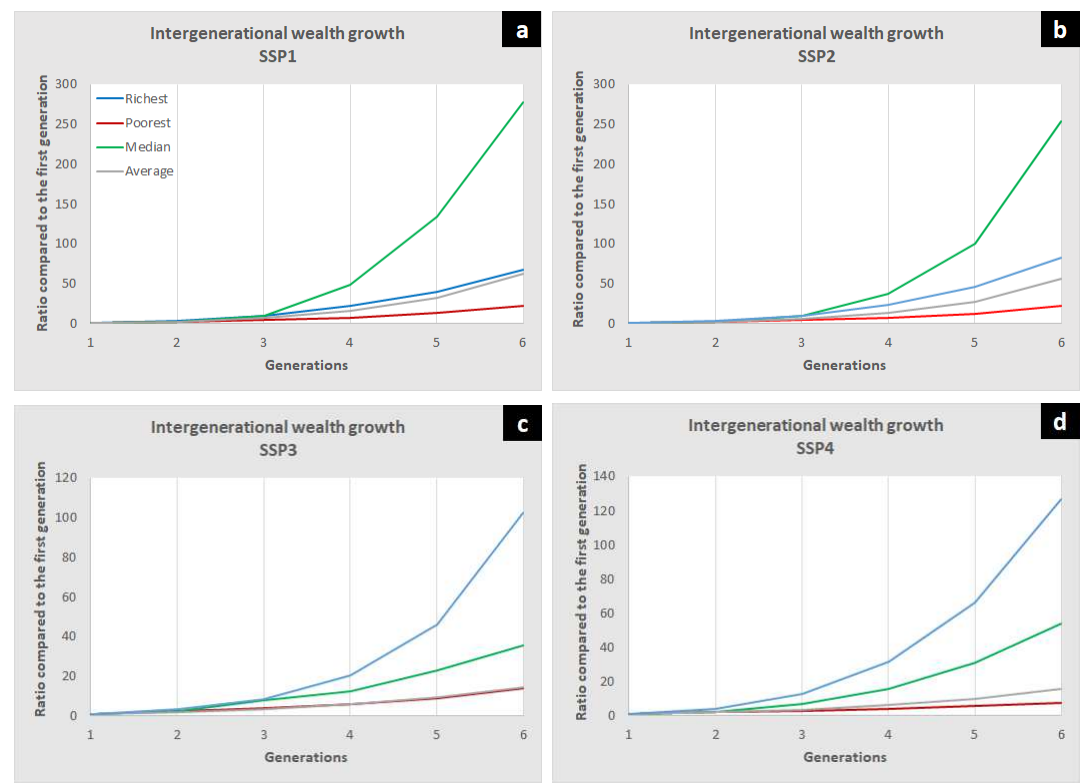

c
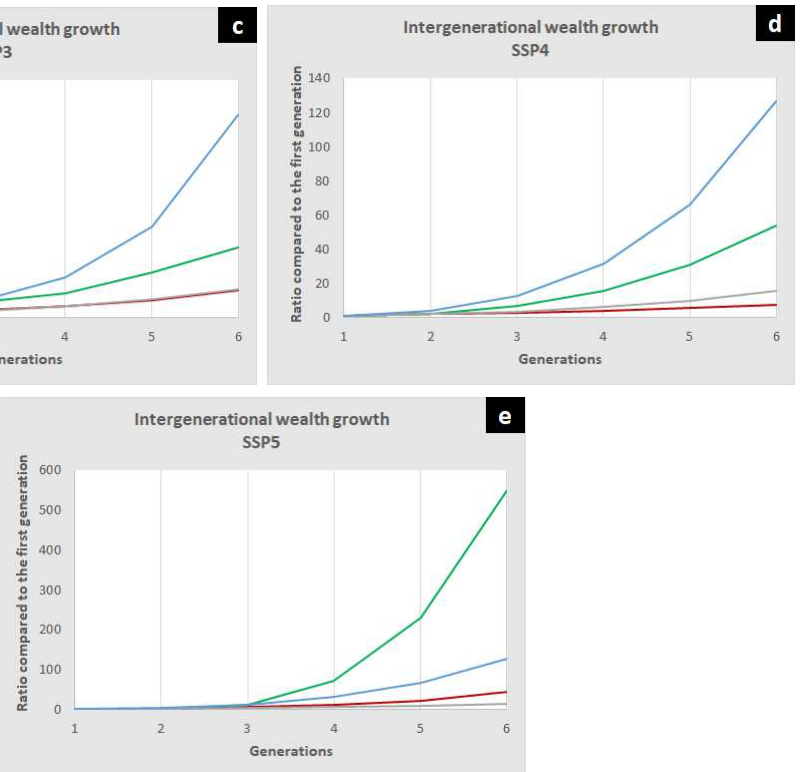

Fig. 3: Intergenerational wealth growth across SSP scenarios for different subpopulations: (a) SSP1, (b) SSP2, (c) SSP3, (d) SSP4, and (e) SSP5. The results are reported as ratio of each sub-population's wealth in each generation to their initial wealth in year 2000 .

\subsection{Capital inheritance and wealth inequality}

One of the features of the proposed OLG model is that the ratio of wages of high-skilled to low-skilled labor is constant and equal to the ratio of childrearing cost as shown in equation (A24) in the Appendix. As a result, the inheritance inequality, and not the income inequality, can be identified as the main driver of the growing wealth gap between different sub-populations. 
Figure 4 shows the distribution of capital inheritance across different generations and SSP scenarios. All scenarios start with a large inequality in capital inheritance in year 2000 which reflects the real situation in South Africa. In the second generation, while a small minority of about $12 \%$ inherits about $70 \%$ of the available capital, other sub-populations stay in the lower end of the capital transfer. In the third generation, we start witnessing a reduction in wealth transfer among the richest families in SSP3 and SSP4 compared to other SSPs while larger portion of the population also fall to the bottom of the inheritance order. In the fourth generation, the sub-populations with lower inherited capital comprise smaller portions of the total population in SSP3 and SSP4 while larger portions of the population start inheriting medium size capitals in SSP1 and SSP5. In the fifth and sixth generations, this trend is even more visible: SSP1, SSP2, and SSP5 have more scattered capital inheritance across different sub-populations which keeps improving the inequality gap while in SSP3 only a very small portion of the population keep receiving capital inheritance. On the other hand, the overall inherited capital SSP4 falls sharply across all population groups. 


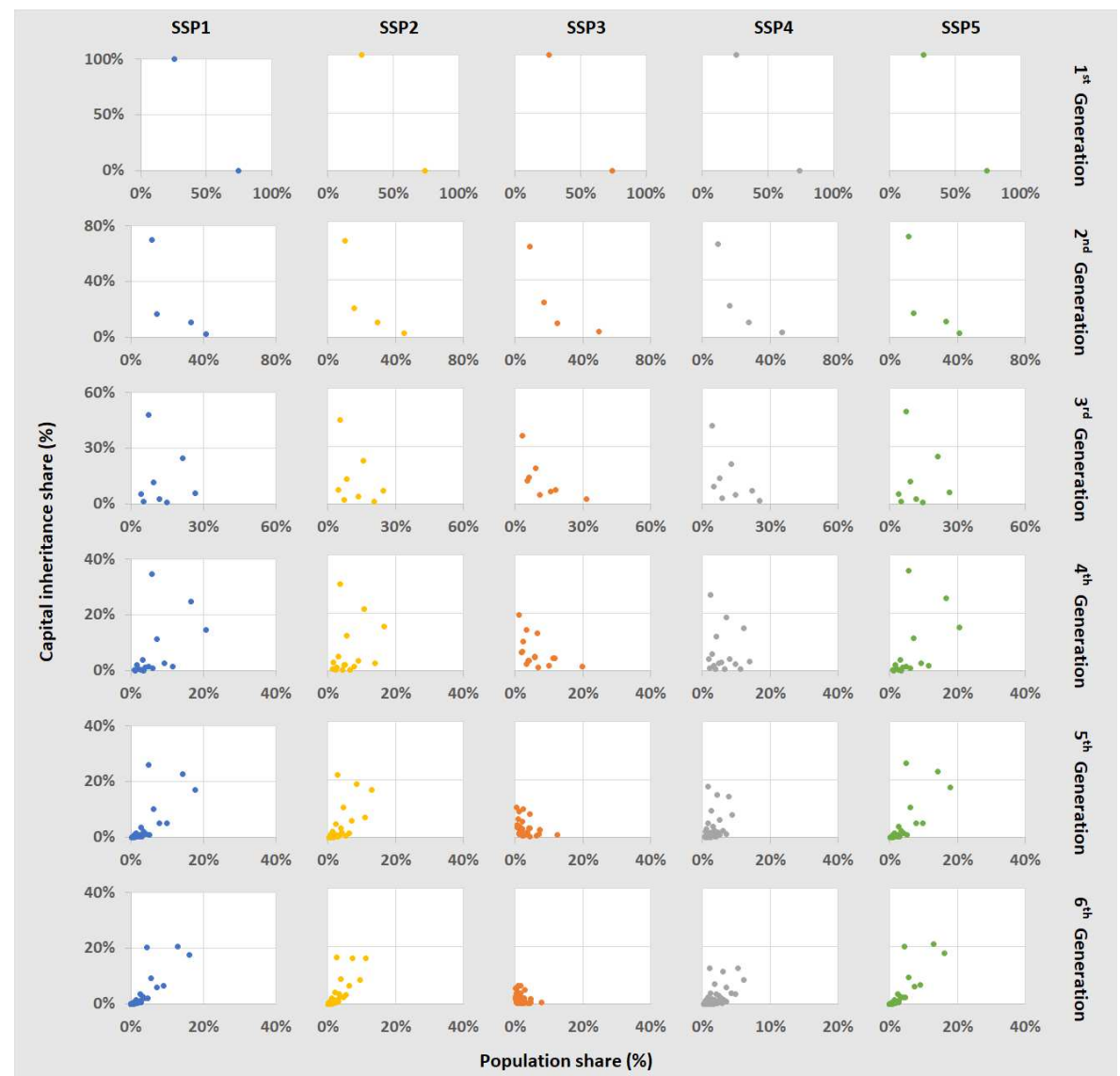

Fig. 4: Distribution of capital inheritance across generations and SSP scenarios.

These capital inheritance trends constitute wealth inequalities in figure 5 . As shown here, the wealth distribution in SSP1, SSP2, and SSP5 becomes more and more equal from the first to the last generation. However the initial inequality, observed in the first generation, persists in SSP3 and SSP4 and the shape of the Lorenz curve remains intact despite the emergence of new sub-populations in higher generations. 


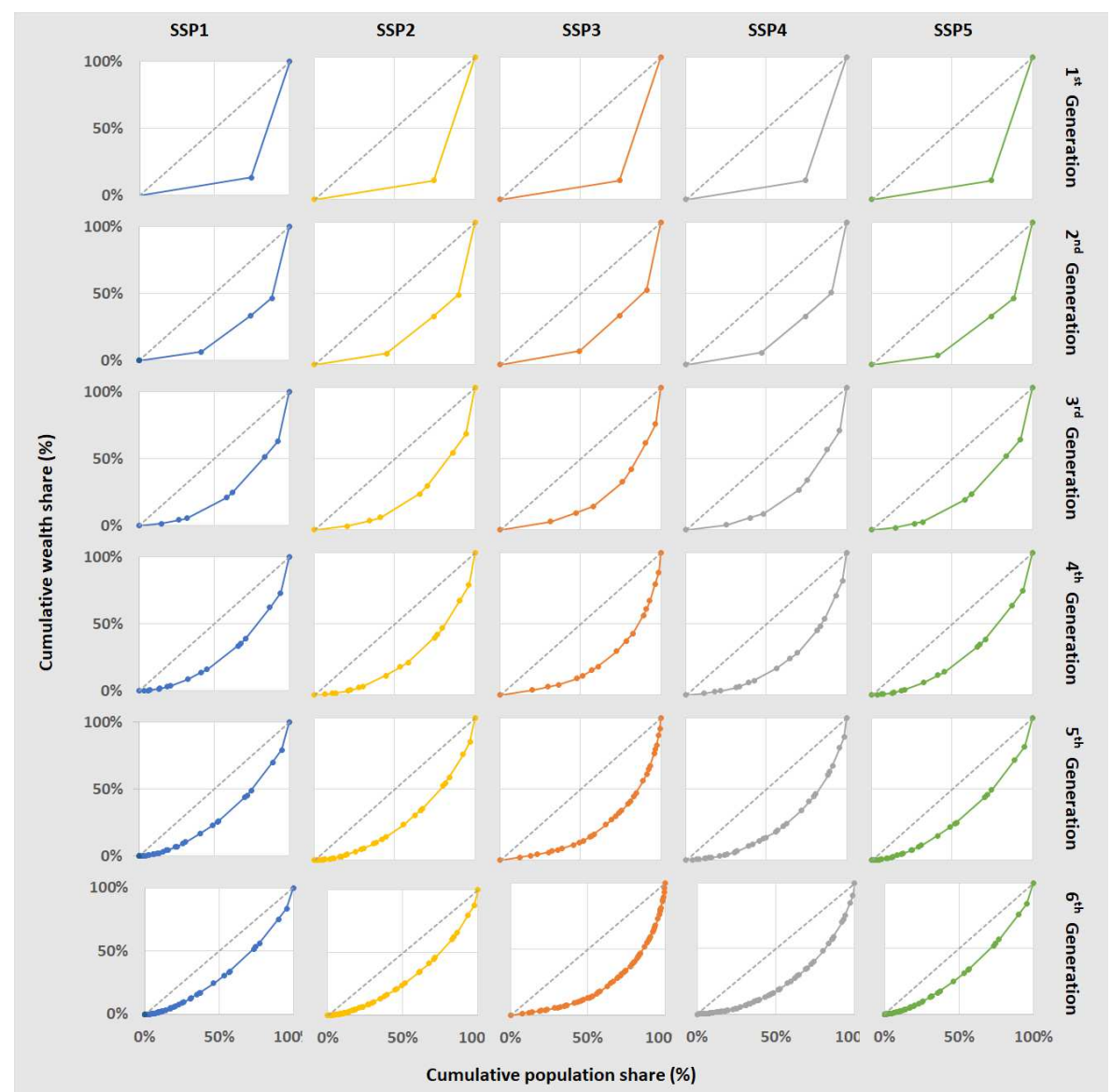

Fig. 5: Lorenz curves showing the wealth distribution across generations and SSP scenarios.

Furthermore, as figure 6 demonstrates, economic growth and human capital development factors can play a significant role in wealth creation and distribution across different SSP scenarios. Panel (a) demonstrate the wealth ratio between the richest and the poorest sub-populations in each generation for each SSP. While SSP1 and SSP5 demonstrate slight increase in the wealth gap, SSP3 and SSP4 are experiencing a rapid growth in wealth difference between the rich and the poor. The overall inequality however, does not only depend on the wealth gap between the two extreme ends of the spectrum, but also 
on how the wealth is distributed across different sub-populations. Panel (b) shows the evolution of the Gini index for each SSP. While the Gini index drops in SSP1 and SSP5 as a result of closing the wealth gap between the rich and the poor, it remains high under SSP3 and SSP4 indicating a slower growth of wealth among the median population in these scenarios.
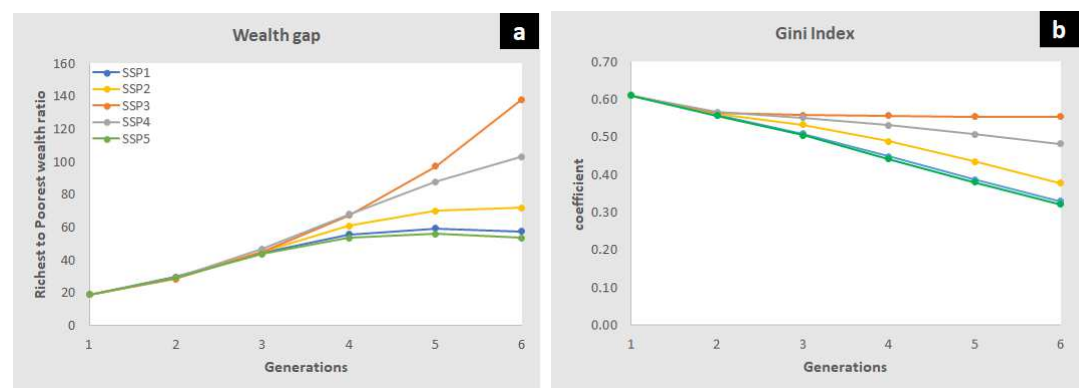

Fig. 6: Impact of climate change on wealth gap and capital gap in South Africa from 2000 to 2100. (a) wealth gap between the richest and the poorest individual in each generation, and (b) capital gap between the richest and the poorest individuals in each generation.

\subsubsection{The impact of inheritance tax}

We can investigate the impact of inheritance tax (i.e., the Estate Duty Act in South Africa) on intergenerational wealth inequality by comparing the results of our modeling exercise with and without implementing the inheritance tax. The results shown in table 1 indicate that the implementation of the Estate Duty Act has a positive but very limited impact on closing the wealth inequality among the future generations in South Africa in certain SSP scenarios. In this table the Gini coefficients are reported for year 2100 for the two cases with and without the inheritance tax. 
Table 1: Estate Duty Act impact on Gini

\begin{tabular}{|cccc|}
\hline Scenario & With Tax & Without Tax & $\Delta$ Gini \\
\hline SSP1 & 0.392 & 0.404 & $1.2 \%$ \\
SSP2 & 0.436 & 0.447 & $1.1 \%$ \\
SSP3 & 0.595 & 0.599 & $0.4 \%$ \\
SSP4 & 0.535 & 0.539 & $0.4 \%$ \\
SSP5 & 0.377 & 0.395 & $1.8 \%$ \\
\hline
\end{tabular}

\section{Discussion and conclusion}

In this paper, we study the evolution of income inequality and wealth distribution in South Africa in the $21^{\text {st }}$ century under 5 shared socioeconomic pathways (SSPs). By constructing a simple but powerful structural model of household dynamics through an overlapping generation model, we capture the human capital accumulation and economic growth dynamics underlying different SSP scenarios. We develop an endogenous mechanism for wealth accumulation through wages and and intergenerational capital inheritance. Our model shows that the gap between the wealthiest and the poorest increases rapidly over generations under SSP3 and SSP4 scenarios due to the slow accumulation of human capital and lower economic growth rates. Higher number of low-skilled labor in these scenarios translates into lower wages and lower wealth creation among the low-skilled and low-income groups.

On the other hand, the fast growth of wealth among median groups under SSP1, SSP2, and SSP5 means the groups with mixed background (e.g., highskilled children of low-skilled parents) have a better chance of catching up with their peers in the richest sub-population. Therefore, as we observe in panel (b) in figure 4, the wealth inequality measured by the Gini index is shrinking under these scenarios.

Overall, our model demonstrates the important role of wealth inheritance in the income distribution dynamics. In line with Piketty and Zucman (2015) who argue the long-run concentration and inheritance will continue to rise 
because of the slowdown of economic growth and the rising competition to attract capital, we show that this increasing wealth concentration trend is more severe in scenarios with slower economic growth and lower human capital accumulation outlook. Therefore, our paper contributes to this argument by providing a theoretical framework to account for wealth creation dynamics within different economic sectors and among different socioeconomic groups.

Our proposed framework could also be used to model the long-term impact of inheritance tax on inequality across generations as the idea of wealth taxation has started to gain more traction among academic community and policy makers in recent years (Kindermann et al, 2020). Another potential extension is to include the link between capital return and environmental factors such as climate change, and investigate the inequality dynamics in this setting as SSP scenarios have an underlying assumptions about sustainability and environmental considerations. Nevertheless, we hope our current contribution paves the way for future research in the field of inequality and sustainable development.

\section{Declarations}

- Funding: This project has received funding from the European Union's Horizon 2020 research and innovation programme under grant agreements No 821124 - NAVIGATE - Next generation of AdVanced InteGrated Assessment modelling to support climaTE policy making.

- Conflict of Interest: The authors declare that they have no conflict of interest. 


\section{Appendix A Model description}

In our model individuals live for 2 periods and can be either high-skilled $(s)$ or low-skilled $(u)$ depending on the education level assigned by their parents. Each period lasts for 20 years and the model runs for 100 years from year 2000 to year 2100. In the first period of their lives, the individuals are children that only consume parental wealth. In our model, a child of type $j$ consumes $\tau^{j}$ units of their parent's wealth which is different for children with different skill levels. In the second period of their life, they will be adults working in one of the economic sectors and earn wages in addition to the capital they have inherited from their parents. In this period, they work, consume goods, and will have their own children. The objective of each individual is to maximize lifetime utility of their consumption, the capital inheritance passed to their children, and the children's future well-being. Parents achieve this goal by making consumption, inheritance, and fertility decisions. The consumption and production are distinguished by their type (agricultural (a) or non-agricultural $(b)$ ) while the capital is either productive $(p)$ or non-productive $(n)$. The productive capital consists of agricultural and non-agricultural capitals that will be aggregated across population in each generation and will be used for economic production in each sector.

\section{A.1 Preferences}

The adult utility function has two components: immediate consumption and future children's wages based on their skill and gender. This captures the altruistic attitude of parents:

$$
\begin{aligned}
v\left(c_{t}^{a}, c_{t}^{b}, H_{t+1}^{p}, H_{t+1}^{n}, n_{t}^{u}, n_{t}^{s}\right) & =\gamma_{1} \ln \left(c_{t}^{a}\right)+\gamma_{2} \ln \left(c_{t}^{b}\right) \\
& +\gamma_{3} \ln \left(H_{t+1}^{p}\right)+\gamma_{4} \ln \left(H_{t+1}^{n}\right)
\end{aligned}
$$




$$
+\left(1-\gamma_{1}-\gamma_{2}-\gamma_{3}-\gamma_{4}\right) \ln \left(\sum_{i=u, s} n_{t}^{i} w_{t+1}^{i}\right)
$$

where $n_{t}^{i}$ is the number of children with skill level $i, c_{t}^{j}$ is consumption of good $j$ that can be either agricultural ( $a$ ) or non-agricultural $(b)$. The intergenerational wealth transfer on the other hand, can be in the form of either productive capital $H_{t+1}^{p}$ including agricultural and non-agricultural capital, or non-productive capital $H_{t+1}^{n}$ such as real estate investments that are passed to the next generation. Future wages of children with skill level $i$ is denoted by $w_{t+1}^{i}$. Parents have preferences over own consumption, their children's inheritance, and the children's expected lifetime earnings. We normalize the price of the agricultural good to derive the budget constraint corresponding to (A1) for every adult:

$$
c_{t}^{a}+P_{t}^{b} c_{t}^{b}+H_{t+1}^{p}+H_{t+1}^{n}=\left(1-\sum_{i=u, s} n_{t}^{i} \tau^{i}\right)[\underbrace{w_{t}+\left(1+\rho_{t}-\delta\right) k_{t}}_{\Omega_{t}}]
$$

where $\tau^{i}$ is the portion of parental time spent on raising a child with skill level $i$, the price of non-agricultural good is denoted by $P_{t}^{b}$. Each adult's wealth $\left(\Omega_{t}\right)$ is measured by their wage $w_{t}$ and the level of capital they own $k_{t}$. The capital is used in production and yields $\rho_{t}$ as rent while $\delta$ accounts for capital depreciation.

The cumulative productive or non-productive capital available in each generation can be obtained from

$$
\begin{aligned}
& \bar{K}_{t+1}^{p}=H_{t+1}^{p} N_{t} \\
& \bar{K}_{t+1}^{n}=H_{t+1}^{n} N_{t}
\end{aligned}
$$


where $N_{t}$ is the adult population at time $t$ and $\bar{K}_{t+1}^{p}$ and $\bar{K}_{t+1}^{n}$ are aggregated productive and non-productive capital inherited from the parents of each generation. The productive capital $\bar{K}_{t+1}^{p}$ will be further divided into agricultural and non-agricultural capital and will be used in the production of goods in each sector:

$$
\bar{K}_{t+1}^{p}=\bar{K}_{t+1}^{a}+\bar{K}_{t+1}^{b}
$$

\section{A.1.1 Inheritance Tax}

The inheritance tax $(T a x)$ is calculated according to the Estate Duty Act in South Africa and will be applied to the non-productive inheritable capital $H_{t+1}^{n}$ :

$$
\begin{array}{ll}
\operatorname{Tax}_{t+1}=0, & \text { if } H_{t+1}^{n}<225 k \\
\operatorname{Tax}_{t+1}=20 \% \times\left(H_{t+1}^{n}-225 k\right), & \text { if } 225 k<H_{t+1}^{n}<2 m \\
\operatorname{Tax}_{t+1}=355 k+25 \% \times\left(H_{t+1}^{n}-2 m\right), & \text { if } 2 m<H_{t+1}^{n}
\end{array}
$$

The net non-productive inheritable capital after tax is calculated as

$$
H_{t+1}^{n n}=H_{t+1}^{n}-\operatorname{Tax}_{t+1}
$$

The productive and non-productive inheritance will be divided among the children of each parent proportional to the time required for their education. For a child with skill level $i$ we have

$$
\begin{aligned}
& k_{t+1}^{i, p}=\frac{H_{t+1}^{p} \tau^{i}}{n_{t}^{u} \tau^{u}+n_{t}^{s} \tau^{s}} \\
& k_{t+1}^{i, n}=\frac{H_{t+1}^{n n} \tau^{i}}{n_{t}^{u} \tau^{u}+n_{t}^{s} \tau^{s}}
\end{aligned}
$$


The total capital allocated to each individual with skill level $i$ therefore, is the sum of these two inherited capitals:

$$
k_{t+1}^{i}=k_{t+1}^{i, p}+k_{t+1}^{i, n}
$$

Maximization of equation (A1) subject to equation (A2) yields:

$$
\begin{aligned}
c_{t}^{a} & =\gamma_{1} \Omega_{t} \\
P_{t}^{b} c_{t}^{b} & =\gamma_{2} \Omega_{t} \\
H_{t+1}^{p} & =\gamma_{3} \Omega_{t} \\
H_{t+1}^{n} & =\gamma_{4} \Omega_{t} \\
\tau_{t}^{u} n_{t}^{u}+\tau_{t}^{s} n_{t}^{s} & =1-\gamma_{1}-\gamma_{2}-\gamma_{3}-\gamma_{4} .
\end{aligned}
$$

Equations (A9)-(A13) demonstrate several important characteristics of the model. First, equation (A13) shows the quantity-quality trade-off in raising children. Because we have $\tau_{t}^{s}>\tau_{t}^{u}$ and the portion of resources devoted to raising children $\left(1-\sum_{n=1}^{4} \gamma_{n}\right)$ is constant at each time period, individuals must decide between investing in smaller number of children but with higher skills and higher potential income and having a greater number of total children with lower skills and lower potential income. Second, comparing equations (A11) and (A12), the following relationship holds between the optimal level of agricultural and non-agricultural capital transferred to the next generation:

$$
\frac{H_{t+1}^{p}}{H_{t+1}^{n}}=\frac{\gamma_{3}}{\gamma_{4}}
$$


Finally, for individuals to have both types of children, it must be the case that:

$$
\tau^{r}=\frac{\tau^{s}}{\tau^{u}}=\frac{w_{t+1}^{s}}{w_{t+1}^{u}}=w_{t+1}^{r}
$$

This equation shows that at each time step the ratio of wages of labor is equal to the ratio of child rearing costs.

\section{A.2 Production}

We adopt a standard two-factor Cobb-Douglas production function with capital and labor as inputs of the production. The profit maximization in each sector can be written as

$$
\begin{gathered}
\operatorname{Max}\left\{Y_{t}^{a}-w_{t}^{u} L_{t}^{u}\right\} \\
\text { s.t. } Y_{t}^{a}=A_{t}^{a}\left(L_{t}^{u, a}\right)^{\alpha}\left(\bar{K}_{t}^{a}\right)^{1-\alpha} \\
\operatorname{Max}\left\{P_{t}^{b} Y_{t}^{b}-w_{t}^{s} L_{t}^{s}\right\} \\
\text { s.t. } Y_{t}^{b}=A_{t}^{b}\left(L_{t}^{s, b}\right)^{\beta}\left(\bar{K}_{t}^{b}\right)^{1-\beta}
\end{gathered}
$$

where $Y_{t}^{a}$ and $Y_{t}^{b}$ are outputs in agricultural and non-agricultural sectors respectively. $L_{t}^{i}$ is the number of labor with skill level $i$. Total factor of productivity (TFP) or technological change in sector $j$ is defined as $A_{t}^{j}$, and $\bar{K}_{t}^{j}$ is the aggregated capital of type $j$ allocated to production in sector $j$ as defined in equation (A4). $\mathrm{T}$

Technological change in both sectors evolves exogenously following an exponential growth model with the growth rate of $\eta$ which is equal to the growth 
rate of total output under each SSP scenario:

$$
A_{t}^{j}=(1+\eta) A_{t-1}^{j}, \quad j=a, b
$$

The number of labor with skill level $i$ will be calculated from multiplying the adult population $N_{t}$ with their number of children with education level $i$ :

$$
L_{t+1}^{i}=N_{t} n_{t}^{i}, \quad i=u, s
$$

Wages of labor with different skill levels can be calculated in each sector by solving maximization problems in equations (A16) and (A17):

$$
\begin{aligned}
& w_{t}^{u}=\alpha A_{t}^{a}\left(L_{t}^{u}\right)^{\alpha-1}\left(\bar{K}_{t}^{a}\right)^{1-\alpha} \\
& w_{t}^{s}=P_{t}^{b} \beta A_{t}^{b}\left(L_{t}^{s}\right)^{\beta-1}\left(\bar{K}_{t}^{b}\right)^{1-\beta}
\end{aligned}
$$

Similarly, capital rent can be calculated as

$$
\begin{aligned}
& \rho_{t}^{a}=(1-\alpha) A_{t}^{a}\left(L_{t}^{u}\right)^{\alpha}\left(\bar{K}_{t}^{a}\right)^{-\alpha}, \\
& \rho_{t}^{b}=P_{t}^{b}(1-\beta) A_{t}^{b}\left(L_{t}^{s}\right)^{\beta}\left(\bar{K}_{t}^{b}\right)^{-\beta} .
\end{aligned}
$$

To solve the model, it is necessary to find the number of children of each skill level (i.e., $n_{t}^{i}$ for $i=u, s$ ). Combining equations (A20) to (A21) will give us

$$
\frac{w_{t}^{s}}{w_{t}^{u}}=P_{t}^{b} \frac{\beta}{\alpha}\left(\frac{A_{t}^{b}}{A_{t}^{a}}\right)\left(\frac{\left(L_{t}^{s}\right)^{\beta-1}}{\left(L_{t}^{u}\right)^{\alpha-1}}\right) \frac{\left(\bar{K}_{t}^{b}\right)^{1-\beta}}{\left(\bar{K}_{t}^{a}\right)^{1-\alpha}}=\tau^{r}
$$


Similarly we can use the fact that the capital rent is equal in both sectors and by dividing equations (A22) and (A23) we have

$$
\frac{\rho_{t}^{b}}{\rho_{t}^{a}}=P_{t}^{b}\left(\frac{1-\beta}{1-\alpha}\right)\left(\frac{A_{t}^{b}}{A_{t}^{a}}\right) \frac{\left(L_{t}^{s}\right)^{\beta}}{\left(L_{t}^{u}\right)^{\alpha}} \frac{\left(\bar{K}_{t}^{b}\right)^{-\beta}}{\left(\bar{K}_{t}^{a}\right)^{-\alpha}}=1
$$

which can be re-written as:

$$
P_{t}^{b}\left(\frac{1-\beta}{1-\alpha}\right)\left(\frac{Y_{t}^{b}}{Y_{t}^{a}}\right)\left(\frac{\bar{K}_{t}^{b}}{\bar{K}_{t}^{a}}\right)^{-1}=1
$$

Now by comparing equations (A24) and (A25) we have

$$
\left(\frac{\beta}{1-\beta}\right)\left(\frac{1-\alpha}{\alpha}\right)\left(\frac{L_{t}^{s}}{L_{t}^{u}}\right)^{-1}\left(\frac{\bar{K}_{t}^{b}}{\bar{K}_{t}^{a}}\right)=\tau^{r}
$$

\section{A.3 Model calibration}

To run the model we use the parameter values specified in table (A1). For the calibration of the model we use the initial values of some variables in year 2000. We specify these values in blue in the following equations. The assigned values of these variables come from table (A2) at the end.

Table A1: Key parameters of the OLG model

\begin{tabular}{clc}
\hline Name & Description & Value \\
\hline$\alpha$ & Agricultural output elasticity of labor & 0.8 \\
$\beta$ & Non-agricultural output elasticity of labor & 0.4 \\
$\delta$ & Capital depreciation rate & $10 \%$ \\
$\gamma_{1}$ & Utility coefficient of agri. consumption & 0.2 \\
$\gamma_{2}$ & Utility coefficient of non-agri. consumption & 0.2 \\
$\gamma_{3}$ & Utility coefficient of productive inheritance & 0.2 \\
$\gamma_{4}$ & Utility coefficient of non-productive inheritance & 0.2 \\
\hline
\end{tabular}


We start the calibration procedure by calculating the ratio of child raring $\operatorname{costs} \tau^{r}$ which is obtained from applying equation (A15) to the wages of highskilled and low-skilled labor in year 2000:

$$
\tau^{r}=w_{2000}^{r}
$$

Next, given the number of high-skilled and low-skilled labor in year 2000, from equation (A27) we can obtain the ratio of non-agriculture to agriculture capital in year 2000:

$$
\bar{K}_{2000}^{r}=\left(\frac{\bar{K}_{2000}^{b}}{\bar{K}_{2000}^{a}}\right)=\left(\frac{1-\beta}{\beta}\right)\left(\frac{\alpha}{1-\alpha}\right)\left(\frac{L_{2000}^{s}}{L_{2000}^{u}}\right)\left(\tau^{r}\right)^{-1}
$$

Given the ratio of non-agricultural to agricultural output $Y_{2000}^{r}=\frac{Y_{2000}^{b}}{Y_{2000}^{a}}$, we can compute the relative price of non-agricultural output (i.e., assuming $P_{2000}^{a}=1$ ) from equation (A26)

$$
P_{2000}^{b}=\left(\frac{1-\alpha}{1-\beta}\right)\left(Y_{2000}^{r}\right)^{-1}\left(\frac{\bar{K}_{2000}^{b}}{\bar{K}_{2000}^{a}}\right)
$$

Having the relative price of non-agricultural output we can calculate the amount of agricultural and non-agricultural output from the following equations:

$$
\begin{aligned}
Y_{2000}^{a} & =\frac{Y_{2000}}{\left(1+P_{2000}^{b} Y_{2000}^{r}\right)} \\
Y_{2000}^{b} & =\frac{\left(Y_{2000}-Y_{2000}^{a}\right)}{P_{2000}^{b}}
\end{aligned}
$$

To calculate the amount of capital in each category, we first divide the total available capital in year 2000 between productive and non-productive capital 
according to equation (A14):

$$
\begin{aligned}
& H_{2000}^{p}=\frac{\gamma_{3}}{\left(\gamma_{3}+\gamma_{4}\right)} K_{2000} \\
& H_{2000}^{n}=\frac{\gamma_{4}}{\left(\gamma_{3}+\gamma_{4}\right)} K_{2000}
\end{aligned}
$$

The non-agriculture capital and agriculture capital are then derived from the productive capital:

$$
\begin{aligned}
\bar{K}_{2000}^{b} & =\frac{\bar{K}_{2000}^{r}}{\left(1+\bar{K}_{2000}^{r}\right)} H_{2000}^{p} \\
\bar{K}_{2000}^{a} & =\frac{1}{\left(1+\bar{K}_{2000}^{r}\right)} H_{2000}^{p}
\end{aligned}
$$

The initial level of total factor productivity (TFP) in each sector is

$$
\begin{aligned}
& A_{2000}^{b}=\frac{Y_{2000}^{b}}{\left(L_{2000}^{s}\right)^{\beta}\left(\bar{K}_{2000}^{b}\right)^{1-\beta}} \\
& A_{2000}^{a}=\frac{Y_{2000}^{a}}{\left(L_{2000}^{u}\right)^{\alpha}\left(\bar{K}_{2000}^{a}\right)^{1-\alpha}}
\end{aligned}
$$

We use the projection of GDP in 2100 to calculate the average growth rate of technology in both sectors

$$
A_{g}^{s s p}=\left(\frac{Y_{2100}^{s s p}}{Y_{2000}}\right)^{1 / 5}-1
$$

where $A_{g}^{s s p}$ is the 20-year growth rate of TFP in both sectors.

The initial low-skilled and high-skilled wages, and the capital rent are calculated using equations (A20), (A21), and (A22) respectively

$$
w_{2000}^{u}=\alpha A_{2000}^{a}\left(L_{2000}^{u}\right)^{\alpha-1}\left(\bar{K}_{2000}^{a}\right)^{1-\alpha},
$$




$$
\begin{aligned}
& w_{2000}^{s}=P_{2000}^{b} \beta A_{2000}^{b}\left(L_{2000}^{s}\right)^{\beta-1}\left(\bar{K}_{t}^{b}\right)^{1-\beta} \\
& \rho_{2000}=(1-\alpha) A_{2000}^{a}\left(L_{2000}^{u}\right)^{\alpha}\left(\bar{K}_{2000}^{a}\right)^{-\alpha},
\end{aligned}
$$

Finally, we calibrate the model to generate the initial Gini index of South Africa in year 2000. We first calculate the wealth share of low-skilled labor $S_{2000}^{u}$ by subtracting the initial Gini from the low-skilled share of total labor

$$
S_{2000}^{u}=\left(\frac{L_{2000}^{u}}{L_{2000}^{u}+L_{2000}^{s}}\right)-G i n i_{2000} / 100
$$

Therefore, the allocation of the initial capital between low-skilled and highskilled labor $\left(K_{2000}^{u}\right.$ and $\left.K_{2000}^{s}\right)$ is done by solving the following equations simultaneously

$$
\begin{aligned}
\frac{S_{2000}^{u}}{1-S_{2000}^{u}} & =\frac{L_{2000}^{u}\left(w_{2000}^{u}+\left(1+\rho_{2000}-\delta\right) K_{2000}^{u}\right)}{L_{2000}^{s}\left(w_{2000}^{s}+\left(1+\rho_{2000}-\delta\right) K_{2000}^{s}\right)} \\
K_{2000} & =K_{2000}^{u}+K_{2000}^{s}
\end{aligned}
$$

Table (A2) shows the values assigned for the key parameters of the model and the initial values of the variables for the calibration procedure.

\section{Solution}

At any time step $t$, parents are deciding about the key variables of the model, including:

- $L_{t}^{u}$ : the number of low-skilled adults in the agricultural sector,

- $L_{t}^{s}$ : the number of high-skilled adults in the non-agricultural sector,

- $\frac{\bar{K}_{t}^{b}}{\bar{K}_{t}^{a}}$ : the ratio of inherited aggregated non-agricultural to agricultural capital. 
To find these variables, we consider equations (A13) and (A27) in addition to the skill ratio $\frac{L_{t}^{s}}{L_{t}^{u}}$ provided from SSP projections.

Table A2: Initial values used for calibration of the OLG model

\begin{tabular}{|c|c|c|}
\hline Name & Description & Value \\
\hline$w_{2000}^{r}$ & High-skilled to Low-skilled wage ratio $^{1}$ & $22600 / 4380$ \\
\hline$L_{2000}^{s}$ & High-skilled labor population (million) ${ }^{2}$ & 7.5873 \\
\hline$L_{2000}^{u}$ & Low-skilled labor population (million) ${ }^{2}$ & 22.0983 \\
\hline$Y_{2000}^{r}$ & ratio of non-agricultural ${ }^{3}$ to agricultural $^{4}$ output & $0.17 / 0.03$ \\
\hline$Y_{2000}$ & Total economic output (billion USD 2005) ${ }^{2}$ & 336.204 \\
\hline$K_{2000}$ & Total capital (billion USD 2005) $)^{5}$ & $0.15745 \times Y_{2000}$ \\
\hline Gini $_{2000}$ & Gini index ${ }^{6}$ & 63 \\
\hline$Y_{2100}^{1}$ & Total output projection under SSP1 (billion USD 2005) ${ }^{2}$ & 2881.139 \\
\hline$Y_{2100}^{2}$ & Total output projection under SSP2 (billion USD 2005) ${ }^{2}$ & 2850.145 \\
\hline$Y_{2100}^{3}$ & Total output projection under SSP3 (billion USD 2005) ${ }^{2}$ & 1985.057 \\
\hline$Y_{2100}^{4}$ & Total output projection under SSP4 (billion USD 2005) ${ }^{2}$ & 1164.627 \\
\hline$Y_{2100}^{5}$ & Total output projection under SSP5 (billion USD 2005) ${ }^{2}$ & 5270.895 \\
\hline
\end{tabular}

${ }^{1}$ Trading Economics:

https://tradingeconomics.com/south-africa/indicators

${ }^{2}$ IIASA SSP Database:

https://tntcat.iiasa.ac.at/SspDb

${ }^{3}$ The World Bank Database (share of agriculture value added as \% of GDP):

https://data.worldbank.org/indicator/NV.AGR.TOTL.ZS?locations=ZA

${ }^{4}$ The World Bank Database (share of manufacturing value added as \% of GDP):

https://data.worldbank.org/indicator/NV.IND.MANF.ZS?locations=ZA

${ }^{5}$ The World Bank Database (Gross capital formation as \% of GDP):

https://data.worldbank.org/indicator/NE.GDI.TOTL.ZS?locations=ZA

${ }^{6}$ The World Bank Database (Gini index):

https://data.worldbank.org/indicator/SI.POV.GINI?locations=ZA

\section{References}

Acemoglu D (2002) Technical Change, Inequality, and the Labor Market. Journal of Economic Literature p 66

Acemoglu D (2003) Patterns of Skill Premia. Review of Economic Studies 70(2):199-230. https://doi.org/10.1111/1467-937X.00242, URL https: //academic.oup.com/restud/article-lookup/doi/10.1111/1467-937X.00242 
Aghion P (2002) Schumpeterian Growth Theory and the Dynamics of Income Inequality. Econometrica 70(3):855-882

Ahluwalia MS, et al (1976) Inequality, poverty and development. Journal of development economics 3(4):307-342

Anand S, Kanbur SR (1993) Inequality and development a critique. Journal of Development economics 41(1):19-43

Arendse J, Stack L (2018) Investigating a new wealth tax in South Africa: Lessons from international experience. Journal of Economic and Financial Sciences 11(1):1-12

Benhabib J, Bisin A, Zhu S (2011) The distribution of wealth and fiscal policy in economies with finitely lived agents. Econometrica 79(1):123-157

Benhabib J, Bisin A, Luo M (2017) Earnings inequality and other determinants of wealth inequality. American Economic Review 107(5):593-97

Berman Y, Ben-Jacob E, Shapira Y (2016) The dynamics of wealth inequality and the effect of income distribution. PloS one 11(4):e0154,196

Casey G, Shayegh S, Moreno-Cruz J, et al (2019) The impact of climate change on fertility. Environmental Research Letters 14(5):054,007

Chatterjee A, Czajka L, Gethin A (2020) Estimating the distribution of household wealth in South Africa. Tech. rep., The United Nations University World Institute for Development Economics Research (UNU-WIDER)

Chatterjee A, Czajka L, Gethin A (2021) A wealth tax for South Africa. Tech. rep., World Inequality Lab 
De Nardi M (2004) Wealth inequality and intergenerational links. The Review of Economic Studies 71(3):743-768

De Nardi M, Yang F (2014) Bequests and heterogeneity in retirement wealth. European Economic Review 72:182-196

Denniga F, Budolfsona MB, Fleurbaeya M, et al (2015) Inequality, climate impacts on the future poor, and carbon prices. PNAS 112(52):15,827-15,832

Diamond PA (1965) National debt in a neoclassical growth model. American Economic Review 55(5):1126-1150

Doyle MW, Stiglitz JE (2014) Eliminating extreme inequality: A sustainable development goal, 2015-2030. Ethics \& International Affairs 28(1):5-13

Elinder M, Erixson O, Waldenström D (2018) Inheritance and wealth inequality: Evidence from population registers. Journal of Public Economics $165: 17-30$

EXPATICA (2021) Inheritance and estate taxes in south africa. URL https://www.expatica.com/za/finance/taxes/ inheritance-tax-in-south-africa-949392/

Francis D, Webster E (2019) Poverty and inequality in South Africa: critical reflections. Development Southern Africa 36(6):788-802

Gabaix X, Lasry JM, Lions PL, et al (2016) The dynamics of inequality. Econometrica 84(6):2071-2111

Galor O (2011) Unified Growth Theory. Princeton University Press 
Grossman GM, Helpman E (2018) Growth, Trade, and Inequality. Econometrica $86(1): 37-83$

Hendricks L (2007) Retirement wealth and lifetime earnings. International Economic Review 48(2):421-456

Hillebrand E (2008) The global distribution of income in 2050. World Development 36(5):727-740

Hopwood B, Mellor M, O'Brien G (2005) Sustainable development: mapping different approaches. Sustainable development 13(1):38-52

Jones CI, Kim J (2018) A schumpeterian model of top income inequality. Journal of Political Economy 126(5):1785-1826

Kindermann F, Mayr L, Sachs D (2020) Inheritance taxation and wealth effects on the labor supply of heirs. Journal of Public Economics 191:104,127

King AD, Harrington LJ (2018) The inequality of climate change from 1.5 to 2 c of global warming. Geophysical Research Letters 45(10):5030-5033

Kok K, Bärlund I, Flörke M, et al (2015) European participatory scenario development: strengthening the link between stories and models. Climatic Change 128(3):187-200

Leibbrandt M, Finn A, Woolard I (2012) Describing and decomposing postapartheid income inequality in South Africa. Development Southern Africa $29(1): 19-34$

Lutz W, Butz WP, Samir K (2014) World Population and Human Capital in the Twenty-First Century. OUP Oxford 
Nolan B, Palomino JC, Van Kerm P, et al (2021) Intergenerational wealth transfers and wealth inequality in rich countries: What do we learn from gini decomposition? Economics Letters 199:109,701

O’Neill BC, Kriegler E, Riahi K, et al (2014) A new scenario framework for climate change research: the concept of shared socioeconomic pathways. Climatic change 122(3):387-400

Piketty T, Zucman G (2015) Wealth and Inheritance in the Long Run. In: Handbook of Income Distribution, vol 2. Elsevier, p 1303-1368

Piketty T, Saez E, Zucman G (2018) Distributional National Accounts: Methods and Estimates for the United States*. The Quarterly Journal of Economics 133(2):553-609

Rao ND, Sauer P, Gidden M, et al (2019) Income inequality projections for the shared socioeconomic pathways (ssps). Futures 105:27-39

Rougoor W, Van Marrewijk C (2015) Demography, growth, and global income inequality. World Development 74:220-232

Saez E, Zucman G (2016) Wealth inequality in the united states since 1913: Evidence from capitalized income tax data. The Quarterly Journal of Economics 131(2):519-578

Samir K, Lutz W (2017) The human core of the shared socioeconomic pathways: Population scenarios by age, sex and level of education for all countries to 2100. Global Environmental Change 42:181-192

Shayegh S (2017) Outward migration may alter population dynamics and income inequality. Nature Climate Change 7(11):828-832 
Stewart F (2016) Changing perspectives on inequality and development. Studies in Comparative International Development 51(1):60-80

Wilson F (2011) Historical roots of inequality in south africa. Economic History of Developing Regions 26(1):1-15

Wolff EN (2002) Inheritances and wealth inequality, 1989-1998. American Economic Review 92(2):260-264 